\title{
Glycaspis brimblecombei Moore (Hemiptera:
}

\section{Aphalaridae), the New Exotic Pest of Eucalyptus in Northern Cyprus}

\author{
İsmail Karaca ${ }^{1}$, Mustafa $\mathrm{Avci}^{2}$ and Özlem Güven ${ }^{3}$ \\ 1. Plant Protection Department, Faculty of Agriculture, Süleyman Demirel University, Isparta 32260, Turkey \\ 2. Department of Forest Industry Engineering, Faculty of Forestry, Süleyman Demirel University, Isparta 32260, Turkey \\ 3. Biology Department, Faculty of Science and Art, Kahramanmaraş Sütcü İmam University, Kahramanmaraş 46040, Turkey
}

\begin{abstract}
Eucalypt-feeding psyllids, Glycaspis brimblecombei Moore (Hemiptera: Psylloidea: Aphalaridae), native to the Australian region, has emerged as an aggressive pest on Eucalyptus in many countries as it was described recently in Greece and Turkey. This study aimed to report this invasive species and its parasitoids on Eucalyptus growing area in Northern Cyprus. G. brimblecombei infested leaves were collected and brought to the laboratory for identification and collection of parasitoids emerged from the pest. In this paper, presence of G. brimblecombei and the parasitoid of the red gum lerp psyllid Psyllaephagus bliteus Riek (Hymenoptera: Encyrtidae) were reported for the first time in Northern Cyprus. Detailed information about the pest and its parasitoids were discussed.
\end{abstract}

Key words: Glycaspis brimblecombei, Northern Cyprus, Psyllaephagus bliteus, red gumlerp psyllid.

\section{Introduction}

Eucalyptus (Myrtaceae: Eucalyptus) is a fast growing evergreen tree, mostly native to Australia [1], and has been planted commercially in tropical and subtropical areas all over the world. Eucalyptus is very important and highly used plant for timber, firewood, oil, honeybee foraging and recreation areas. It can be also used for draining of marshes to eradicate malaria. Unfortunately, drying of the soil negatively affects other plant species. Eucalyptus trees were introduced to Cyprus for the first time in 1881 by French Forest Service member, Madon, P. G. for afforestation of Nicosia walls [2].

In spite of various pests reported on Eucalyptus trees [3-6], in the Middle East and the Mediterranean, eucalypt trees were considered almost free of serious insect pests. Australian insects have been introduced and established all over the world and turn into an

Corresponding author: İsmail Karaca, professor, research fields: entomology and biological control. important management issue in most eucalypt growing areas [7, 8]. During the last few years, several insects became established in Eucalyptus trees in Europe [9-13]. One of the most recently introduced species is Glycaspis brimblecombei Moore (Hemiptera: Psyllidae), commonly known as the red gum lerp psyllid, which was considered a serious pest. Production of large amounts of honeydew, on which sooty mould develops and feeds on sap by adults and nymphs, caused leaf discoloration and infested trees becoming susceptible to attacking by secondary pests [10]. Severe and multiple defoliations can result in tree death.

As a part of the psyllid biological control programs, the parasitoid Psyllaephagus bliteus Riek (Hymenoptera: Encyrtidae) was imported from Australia and introduced to several countries, such as California, USA [14], Mexico [15] and Chile [16]. The parasitoid was not intentionally introduced, but probably was established itself in Spain, Italy, Greece and Turkey [9-13, 17]. 
This study aimed to observe and find invasive species, G. brimblecombei and its parasitoid P. bliteus during summer 2015 in North Cyprus.

\section{Materials and Methods}

During 2015, visual inspections of Eucalyptus leaves in several areas showed the presence of adults, nymphs and lerps of G. brimblecombei. Samples were collected from Nicosia (Lefkoşa), Morphou (Güzelyurt), Famagusta (Magusa), where Eucalyptus spp. were planted. This pest was observed in all regions and mostly in Morphou (Güzelyurt).

Heavy infested leaves of Eucalyptus spp. were sampled, wrapped in dry newspaper and then placed in plastic bags to bring to laboratory for detail examinations. Additionally, the leaves were placed into parasitoid extraction box to collect natural enemies. The plastic container was covered with black cover to prevent light entering, and clear plastic tube was attached to plastic container to collect parasitoids, which showed tendency of moving to light. Emerging parasitoids in the clear plastic tube were collected daily. Lerps, adult, eggs on the leaves and immature stages of G. brimblecombei were measured and photographed for identifications (Fig. 1).

The white coverings (lerps) secreted by the nymphs are easily recognized on the infested Eucalyptus leaves. G. brimblecombei was identified by senior author using the important key characters, such as long genal combs, long vertex and apically angulate forewings $[5,10]$. Parasitoid, P. bliteus was identified by Dr. George Japoshvili. All insect samples were stored at Entomological Museum of Ispart, Turkey (EMIT).

\section{Results and Discussion}

G. brimblecombei Moore, 1964 (synonym: Alloglycaspis brimblecombei More, 1961). Observations made on Eucalyptus spp. in several areas of North Cyprus in 2015 confirmed $G$. brimblecombei infestation for the first time. Adults of red gum lerp psyllid are 2-4 mm long, light green-colored on the head with dark red eyes and have a characteristic of long genital processes and elongate forewings [10] (Fig. 1a). Immatures develop under a lerp, shield-like white crystalline cover that is on the leaf surface [5] (Fig. 1b). Lerps are usually whitish in appearance, but may turn to a grey or black color with age. Adults lay spindle-shaped, yellow-orange colored eggs randomly on the leaves. Nymphs are yellow-orange with brown coloration on the wing pads (Fig. 1c).

Parasitoid of the red gum lerp psyllid, P. bliteus Riek (Hymenoptera: Encyrtidae) (synonym: P. bliteus Riek, 1962) was also recorded for the first time in this study in North Cyprus (Fig. 1f). This parasitic wasp feeds only on G. brimblecombei. Females generally lay eggs in the psyllid nymphs and the parasitoid larvae feed on the psyllid, and then metamorphose in the lerp. When the wasp was ready to leave, it will make an emergence hole in the lerp [18].

G. brimblecombei has been reported from many areas where Eucalyptus spp. grown. This insect was first found and identified in Queensland, Australia by Moore [19]. This insect showed very rapid spread in different countries and became a major pest of Eucalyptus trees. Blastopsylla occidentalis Taylor and G. brimblecombei were found in California and Florida, North America [20]. Also, G. brimblecombei was found and reported in Brazil [21], Peru [22], Portugal and Spain [23]. B. occidentalis and G. brimblecombei were reported from Israel for the first time in 2015, and both species were collected from a dominant eucalypt species, E. camaldulensis Dehnh. In Italy, E. camaldulensis is very common eucalypt species and $G$. brimblecombei and generalist predators, such as ants, spiders and pirate bugs, were observed from several urban and rural areas, but psyllid parasitoids were not found [10]. Later on this, the specific parasitoid, P. bliteus was reported in Italy in 2011 [18]. During a survey in 2013 in Tunisia, high G. brimblecombei infestation was observed on Eucalyptus trees [12]. The red gum lerp 


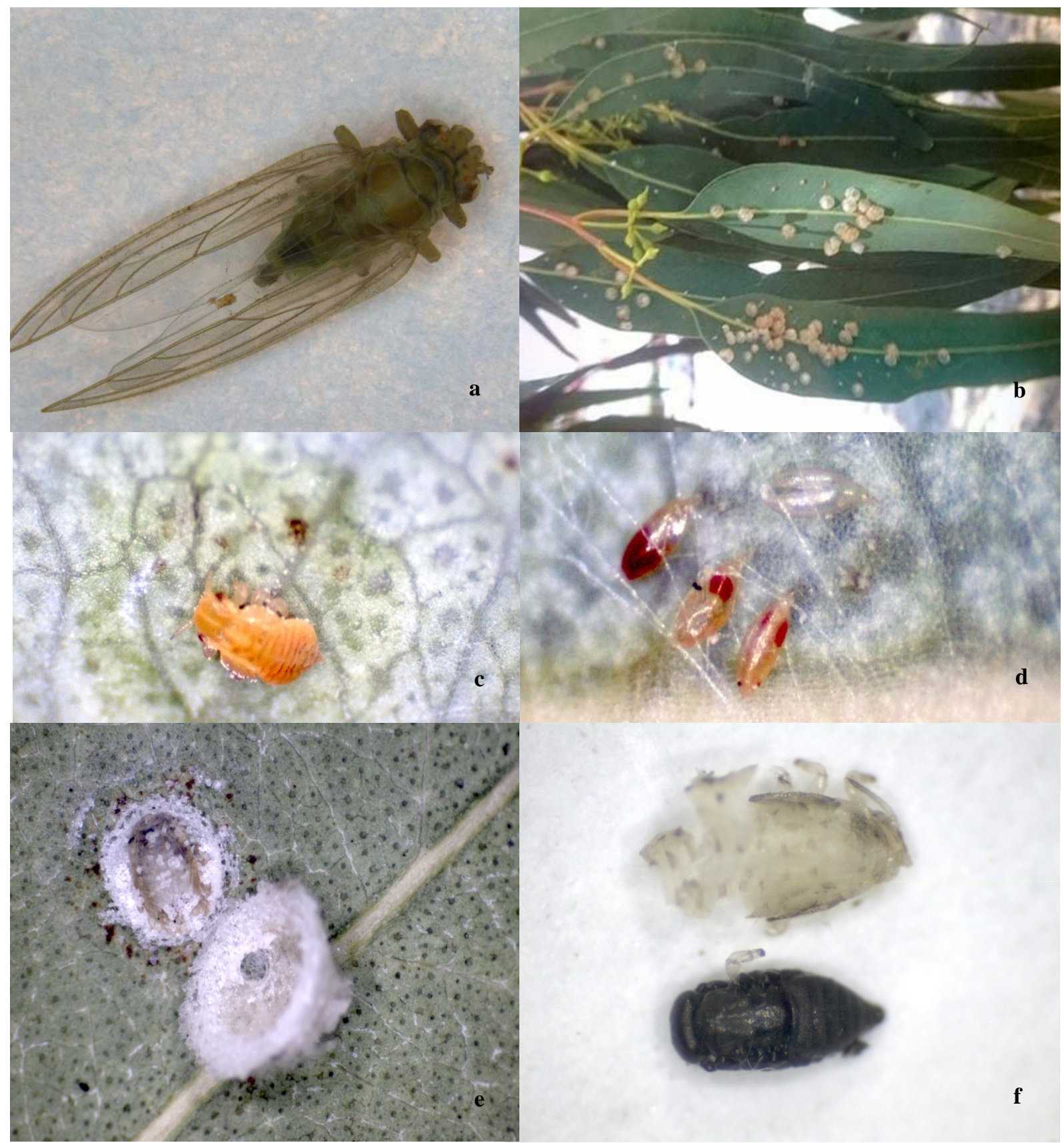

Fig. 1 G. brimblecombei: adult (a), lerps on Eucalyptus spp. leaves (b), nymph (c), eggs (d), parasitized lerps and nymph (e), pupa of $P$. bliteus (f).

psyllid and its parasitoid in Greece were found for the first time during the observations conducted in summer 2013 [11, 17]. After reporting this species in Greece, the occurrence of G. brimblecombei and its parasitoids $P$. bliteus was reported for the first time on E. camaldulensis leaves in İzmir area in Turkey [13].

\section{Conclusions}

The invasive alien species, G. brimblecombei was originated in Australia and became an invasive pest since its establishment overseas in the Middle East and the Mediterranean region in 2000. The establishment of this species in North Cyprus was not surprising, because of its infestation on eucalypt trees 
in other Mediterranean countries, especially in Greece and Turkey. This pest was observed in 2015 in several areas where Eucalyptus spp. was planted in North Cyprus. The establishment of this species in North Cyprus also brought together with its principle parasitoid of $P$. bliteus. The rapid colonization of this pest demands a detail study about its biology, ecology, natural enemies and especially invasion dynamics to understand its potential distribution before causing economic loss.

\section{Acknowledgments}

Sincere thanks are expressed to Dr. George Japoshvili (Institute of Entomology, Agricultural University of Georgia, Tbilisi, Georgia) for the identification of $P$. bliteus. The authors are also grateful to Ferit Güven and Salih Güneş (forest engineer at Directorate of Forestry in North Cyprus) for providing leave samples.

\section{References}

[1] Brooker, M. I. H. 2000. "A New Classification of the Genus Eucalyptus." Australian Systematic Botany 13: 79-148.

[2] Anonymous. 2016. "Types of Eucalyptus Growing in Cyprus." Ministry of Agriculture and Forestry, Turkish Republic of Northern Cyprus. Accessed January 25, 2018. https://www.slideshare.net/halilcandemir/kbrsta-yetien-o kalpts-trleri-1732005.

[3] Gill, R. J. 1998. "New State Records: Redgum Lerp Psyllid, Glycaspis brimblecombei." California Plant Pest and Disease Report 17 (1-3): 7-8.

[4] Paine, T. D., and Millar, J. G. 2002. "Insect Pests of Eucalypts in California: Implications of Managing Invasive Species." Bulletin of Entomological Research 92 (2): $147-52$.

[5] Halbert, S. E., Gill, R., and Nisson, J. N. 2001. "Two Eucalyptus Psyllids New to Florida (Homoptera: Psyllidae)." Florida Department of Agriculture and Consumer Services-Division of Plant Industry (Entomology Circular) 407: 1-2.

[6] Inghilesi, A. F., Cervo, R., Pennacchio, F., Roversi, P. F., Tricarico, E., and Mazza, G. 2013. "Alien Insects on Eucalyptus spp.: An Australian Biocenosis in Tuscany." REDIA, XCVI 96: 21-6.

[7] Withers, T. M. 2001. "Colonization of Eucalypts in New Zealand by Australian İnsects." Austral. Ecology 26:
467-76.

[8] Queiroz, D. L., Majer, J., Burckhardt, D., Zanetti, R., Fernandez, J. I. R., Queiroz, E. C., Garrastazu, M., Fernandes, B. V., and Anjos, N. 2013. "Predicting the Geographical Distribution of Glycaspis brimblecombei (Hemiptera: Psylloidea) in Brazil." Australian Journal of Entomology 52 (1): 20-30.

[9] Borrajo, P., Lopez, G., and Ruiz, F. 2009. "First Report of the Occurrence of Glycaspis brimblecombei Moore (Homoptera, Psyllidae) in SW of Spain.” Boletin de Sanidad Vegetal Plagas 35 (3): 355-61.

[10] Laudonia, S., and Garonna, A. P. 2010. "The Red Gum Lerp Psyllid, Glycaspis brimblecombei, a New Exotic Pest of Eucalyptus camaldulensis in Italy." Bulletin of Insectology 63 (2): 233-6.

[11] Bella, S., and Rapisarda, C. 2013. "First Record from Greece of the Invasive Red Gum Lerp Psyllid Glycaspis brimblecombei Moore (Hemiptera: Psyllidae) and Its Associated Parasitoid Psyllaephagus bliteus Riek (Hymenoptera: Encyrtidae).” REDIA, XCVI 96: 33-5.

[12] Attia, S. B., and Rapisarda, C. 2014. "First Record of the Red Gum Lerp Psyllid, Glycaspis brimblecombei Moore (Hemiptera: Psyllidae), in Tunisia.” Phytoparasitica 42 (4): 535-9.

[13] Karaca, İ., Kayahan, A., Şimşek, B., and Çelikpençe, Y. 2015. "First Record of Glycaspis brimblecombei Moore (Hemiptera: Aphalaridae) in Turkey." Phytoparasitica 43: 171-5.

[14] Paine, T. D., Dahlsten, D. L., Millar, J. G., Hoddle, M. S., and Hanks, L. M. 2000. "UC Scientists Apply IPM Techniques to New Eucalyptus Pests." California Agriculture 54 (6): 8-13.

[15] Plascencia-González, A., Cibrián-Tovar, D., Llanderal-Cázares, C., López-Pérez, I., and Arriola-Padilla, V. 2005. "Biology of Psyllaephagus bliteus (Hymenoptera: Encyrtidae)." Revista Chapingo Serie Ciencias Forestales y del Ambiente 11 (1): 11-7.

[16] Ide, M. S., Muñoz, A. C., Beeche, C. M., Mondaca, E. J., Jaques, R. L., González, P., and Goycoolea, P. C. 2006. Detection and Biological Control of Glycaspis brimblecombei Moore (Hemiptera: Psyllidae). Santiago, Chile: Servicio Agrícola y Ganadero, División de Protección Agrícola, 32.

[17] Tsagkarakis, A. E., Kalaitzaki, A. P., and Balotis, G. N. 2014. "Note on Glycaspis brimblecombei Moore (Hemiptera: Psyllidae): A New Pest of Eucalyptus in Greece." Advances in Entomology 2 (1): 57-9.

[18] Caleca, V., Lo Verde, G., and Maltese, M. 2011. "First Record in Italy of Psyllaephagus bliteus Riek (Hymenoptera: Encyrtidae) Parasitoid of Glycaspis brimblecombei Moore (Hemiptera: Psyllidae)." II Naturalista Siciliana 35 (3-4): 435-44. 


\section{Exotic Pest of Eucalyptus in Northern Cyprus}

[19] Moore, K. M. 1964. "Observations on Some Australian Forest İnsects. 18. Four New Species of Glycaspis (Homoptera: Psyllidae) from Queensland." In Proceedings of the Linnean Society of New South Wales. 89: 163-6.

[20] Brennan, E. B., and Gill, R. J. 1999. "First Record of Glycaspis brimblecombei (Moore) (Homoptera: Psyllidae) in North America: Initial Observations and Predator Associations of a Potentially Serious New Pest of Eucalyptus in California." Pan-Pacific Entomologist 75: 55-7.

[21] Lutinski, J. A., Lutinski, C. J., and Garcia, F. R. M. 2006.
"First Record of Glycaspis brimblecombei Moore 1964, (Hemiptera: Psyllidae) in Eucalyptus in Santa Catarina State, Brazil." Ciência Rural 36 (2): 653-5.

[22] Burckhardt, D., Lozada, P. W., and Diaz, B. W. 2008. "First Record of the Red Gum Lerp Psyllid Glycaspis brimblecombei (Hemiptera: Psylloidea) from Peru." Mitteilungen der Schweizerischen Entomologische Gesellschaft 81: 83-5.

[23] Valente, C., and Hodkinson, I. 2009. "First Record of the Red Gum Lerp Psyllid, Glycaspis brimblecombei Moore (Hem.: Psyllidae), in Europe." Journal of Applied Entomology 133 (4): 315-7. 